\title{
Avaliação in vitro da liberação de níquel por braquetes metálicos
}

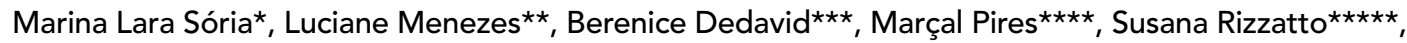

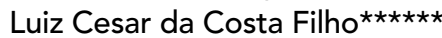

\begin{abstract}
Resumo
O aço inoxidável austenítico é utilizado para confecção de dispositivos ortodônticos e contém cerca de $8-10 \%$ de níquel em sua composição, metal este responsável por reações alérgicas de hipersensibilidade. Acredita-se que a liberação de níquel dos dispositivos metálicos pode provocar dermatites de contato em pacientes suscetíveis. Este estudo laboratorial avaliou a influência de três variáveis na liberação de níquel: 1) o tipo de liga do braquete; 2) o tipo de solução de imersão e 3) o esforço mecânico nas canaletas dos braquetes de aço inoxidável austenítico. Foram avaliados seis grupos experimentais e dois grupos controles. As amostras foram imersas em tubos de ensaio contendo saliva artificial ou solução salina, sendo mantidas sob agitação e temperatura constante $\left(37^{\circ} \mathrm{C}\right)$. A quantidade de níquel presente nas soluções foi avaliada com espectrofotômetro de absorção atômica (Varian - Spectra A55) em dois momentos: após uma semana e após duas semanas. Os resultados revelaram que os braquetes de aço inoxidável com baixo teor de níquel apresentaram menor liberação deste elemento. Foi possível constatar que o tipo de solução alterou o padrão de liberação de níquel pelos dispositivos avaliados. O esforço mecânico aplicado sobre os braquetes de aço inoxidável austenítico não alterou a quantidade de níquel liberada.
\end{abstract}

Palavras-chave: Metais. Ortodontia. Níquel. Braquetes metálicos.

\section{INTRODUÇÃO}

A maioria dos dispositivos metálicos utilizados durante o tratamento ortodôntico é confeccionada com aço inoxidável do tipo austenítico que, entre outros metais, contém em sua liga cerca de $8 \%$ de níquel e $18 \%$ de cromo $^{1,3,14}$.

O níquel tem sido freqüentemente associado a manifestações alérgicas, provocando mais reações do que todos os outros metais combinados ${ }^{21}$. Alguns relatos de casos na literatura sugerem que os dispositivos ortodônticos podem desencadear dermatite de contato em indivíduos sensíveis ${ }^{2,7,15,17}$. Além disso, evidências recentes indicam que o níquel apresente propriedades mutagênicas, citotó-

* Cirurgiã Dentista formada pela FOB-USP e Mestranda em Ortodontia pela PUCRS

** Doutora em Ortodontia pela UFRJ e Professora de Ortodontia na PUCRS.

*** Doutora em Engenharia pela UFRGS e Professora do Programa de Pós-Graduação em Engenharia e Tecnologia de Materiais da PUCRS.

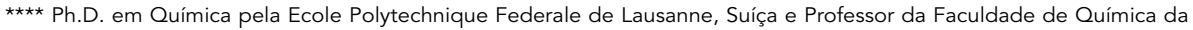
PUCRS.

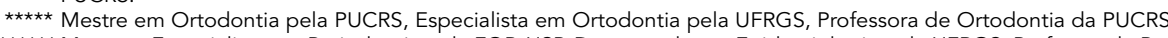

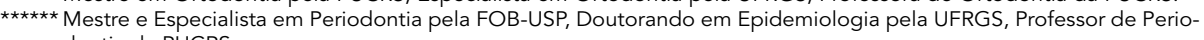
dontia da PUCRS. 
xicas e carcinogênicas ${ }^{18,19}$.

A incidência de hipersensibilidade ao níquel é significativa, variando de 10 a 30\% na população ${ }^{21}$. As mulheres são mais freqüentemente acometidas, numa proporção de 5:1. Suspeita-se que a utilização de bijuterias possa exacerbar a sensibilidade ao $\operatorname{metal}^{11,12,21}$.

A preocupação com a quantidade de níquel liberada por dispositivos que permanecem em contato prolongado com a pele estimulou o Parlamento Europeu a redigir, em 1994, diretrizes e normas para fabricação de produtos metálicos que contenham níquel. Esta norma estabelece que a liberação máxima de níquel deve ser de $0,5 \mu \mathrm{g} / \mathrm{cm}^{2} /$ por semana. Para tanto, é necessário conhecer a área de contato do dispositivo com a pele ou mucosa, além da quantidade semanal de íons metálicos liberados in vitro ${ }^{4}$. Portanto, o conhecimento da quantidade de níquel liberada pelos dispositivos ortodônticos parece ser relevante. Com este objetivo, Park e Shearer ${ }^{20}$ avaliaram a liberação, in vitro, de níquel e cromo de aparelhos ortodônticos, constituídos de bandas para molares e pré-molares, braquetes para caninos e incisivos e fio de aço inoxidável, imersos em solução aquosa de $0,05 \%$ de cloreto de sódio. Verificaram que a liberação de níquel foi de $40 \mu \mathrm{g}$ por dia, valor referente à quantidade de metal presente em aparelhos completos, para arcada superior e inferior, com bandas para todos os dentes posteriores. Relataram também que a liberação de níquel foi progressiva na primeira semana, atingindo um platô a partir do sexto dia.

Barret, Bishara e Quinn ${ }^{1}$ conduziram um experimento laboratorial para quantificar a liberação de níquel por aparelhos ortodônticos com bandas para molares e segundos pré-molares, braquetes para os demais dentes, todos de aço inoxidável dos tipos 303, 304, 305 e 316L. A variável investigada foi o tipo de arco: retangular de aço inoxidável e retangular de Ni-Ti, ambos 0,017" x 0,025". Os aparelhos simulados, sendo cinco para cada tipo de fio a ser avaliado, foram introduzidos em frascos de polietileno com tampa, contendo $100 \mathrm{ml}$ de saliva artificial. $\mathrm{O}$ ambiente do experimento teve sua temperatura controlada $\left(37^{\circ} \mathrm{C}\right)$ e foi dinâmico, ou seja, com agitação constante provida por um equipamento específico para este fim. Nos dias 1, 7, 14, 21 e 28 o conteúdo dos frascos foi completamente removido, sendo reposto pela solução recentemente manipulada. Os resultados demonstraram que a liberação de níquel foi de $26 \mu$ g/dia, correspondente à quantidade de metal presente no aparelho completo (arcadas superior e inferior, com bandas nos dentes posteriores). Os autores relataram que a taxa da liberação de níquel foi crescente na primeira semana, atingindo um platô no sétimo dia, com decréscimo nos dias subseqüentes.

Grimsdottir, Gjerdet e Hensten-Pettersen ${ }^{8}$ avaliaram a quantidade de níquel liberada por arcos extrabucais, bandas, braquetes e fios metálicos isolados, sem que estivessem montados para simular o aparelho ortodôntico. Cinco marcas de cada dispositivo foram avaliadas. Os dispositivos foram colocados em frascos contendo solução aquosa de $\mathrm{NaCl} 0,9 \%$, a $23^{\circ} \mathrm{C}$, durante quatorze dias, com troca completa da solução no sétimo dia.

A maior quantidade de níquel foi encontrada nas soluções que continham os arcos extrabucais, variando consideravelmente conforme a marca do produto. As bandas ortodônticas e os braquetes metálicos também liberaram quantidades significativas de níquel, variando conforme o fabricante. Apesar das variações de liberação entre as marcas comerciais, pôde-se observar que todos os dispositivos avaliados liberaram quantidades crescentes de níquel da primeira para a segunda semana, com exceção dos fios de aço, que apresentaram quantidades despreziveis de níquel nos dois períodos avaliados (Tab. 1).

Os autores Hwang, Shin e $\mathrm{Cha}^{10}$ propuseramse a investigar a liberação in vitro de elementos metálicos pelos dispositivos ortodônticos durante 12 semanas. Para tanto, foram construídos aparelhos simulando um hemi-arco maxilar, composto por bandas braquetes e tubos de aço inoxidável, presos ao fio através de amarrilho elástico. Utilizaram-se dois tipos de arcos, ambos nas dimensões de 0,016 " x 0,022": um de aço inoxidável, que foi tra- 
tado termicamente, e outro de níquel-titânio. Foram montados 320 aparelhos fixos simulados, divididos em quatro grupos, conforme o tipo de fio utilizado e o fabricante do produto. Assim, cada grupo continha 80 amostras, que foram divididas em 8 subgrupos, conforme o período de retirada da solução: dias 1, 3, 7, 21, 28, 35 e 42. Não foi realizada a troca da solução, e sim a retirada de 10 amostras de cada tipo para análise em cada período. Os aparelhos foram imersos em $50 \mathrm{ml}$ de saliva artificial e mantidos em incubadora, sem agitação. Dois grupos controle foram preparados para cada subgrupo. Através da espectrofotometria de absorção atômica quantificaram-se as concentrações de níquel, cromo, ferro, titânio e cobre. Em relação ao níquel, os autores verificaram diferentes padrões de liberação pelos grupos, sendo que alguns foram progressivos com o tempo e outros tendiam a se estabilizar após o sétimo dia.

A influência de esforços mecânicos na liberação de íons por estruturas metálicas foi pesquisada por Tai et al. ${ }^{22}$. Os autores submeteram coroas metálicas confeccionadas com liga de $\mathrm{Ni}-\mathrm{Cr}$ a esforços mastigatórios em simulador oral, especialmente construído para este fim. Doze pares de coroas metálicas anatomicamente idênticas foram articuladas e divididas em quatro grupos, conforme o material utilizado para confecção do dente antagonista: 1) metal contra metal; 2) metal contra porcelana; 3) metal contra esmalte; 4) metal sem submissão à força mastigatória (controle). No simulador havia fluxo contínuo de saliva artificial, na velocidade de $2 \mathrm{ml} / \mathrm{min}$, sendo esta, portanto, continuamente reposta. A temperatura da solução foi controlada em $37^{\circ} \mathrm{C}$ e o $\mathrm{pH}$ ajustado em 5 , para simular a acidez

\begin{tabular}{|c|c|c|}
\hline & Primeira semana & Segunda semana \\
\hline Arco extrabucal & $0,4 \mu \mathrm{g}$ a $7,6 \mu \mathrm{g}$ & $0,5 \mu \mathrm{g}$ a $10,4 \mu \mathrm{g}$ \\
\hline Bandas & $1,3 \mu \mathrm{g}$ a $2,8 \mu \mathrm{g}$ & $2,5 \mu \mathrm{g}$ a $5 \mu \mathrm{g}$ \\
\hline Braquetes & $0,1 \mu \mathrm{g}$ a $2,2 \mu \mathrm{g}$ & $0,3 \mu \mathrm{g}$ a $3,8 \mu \mathrm{g}$ \\
\hline
\end{tabular}

da alimentação diária. A concentração de níquel e berílio na solução foi avaliada no momento inicial (baseline) e também após 1, 3, 6, 9 e 12 meses, tempo que totalizou 300.000 ciclos de mastigação simulada. Os autores encontraram a maior concentração de níquel no grupo 2 (metal contra porcelana) e a menor no grupo 1 (metal contra metal) sendo que o grupo 3 (metal contra esmalte) demonstrou uma quantidade intermediária. Facetas de desgaste foram observadas nas coroas metálicas, o que, segundo os autores, contribui para a dissolução do metal e para a liberação de íons na solução. Foi possível concluir que, em média, uma coroa metálica libera $100 \mu g$ de níquel por dia. Verificouse também que os esforços mastigatórios aumentaram, em até três vezes, a taxa de liberação de níquel por coroas metálicas de Ni-Cr.

Os estudos de liberação de níquel in vitro são heterogêneos, existindo variação nos tipos de ligas metálicas e fabricantes avaliados, além dos aspectos metodológicos como tipo de solução de imersão e temperatura. Estes fatos dificultam a interpretação e aplicação clínica dos dados, pois as várias pesquisas relatadas na literatura não podem ser comparadas diretamente.

Além disso, sabe-se que diversas variáveis interferem no processo de corrosão dos braquetes e, conseqüentemente, na liberação de elementos metálicos no ambiente bucal. Estas variáveis são: processo de fabricação; presença de solda unindo as aletas à base do braquete; tipo de fio utilizado durante o tratamento ortodôntico; intensidade das forças aplicadas na canaleta; processo de polimento e acabamento do braquete; rugosidade superficial dentro e fora da canaleta; microbiota bucal, as enzimas e o $\mathrm{pH}$ da saliva ${ }^{3,6,16}$.

A liberação de níquel no ambiente bucal não é diretamente proporcional ao teor deste elemento na liga metálica. Tal fenômeno ocorre porque a liberação de níquel depende da interação deste com os demais componentes da liga metálica, bem como com o ambiente externo ${ }^{3,16}$. Os fios de níquel-titânio, por exemplo, que possuem cerca de $50 \%$ de níquel em 
sua composição, apresentaram taxas de liberação menores ou semelhantes às dos fios de aço inoxidável, em experimentos laboratoriais ${ }^{1,10}$.

A aplicação de esforços mecânicos sobre estruturas de ligas metálicas pode estimular o processo corrosivo e aumentar a liberação de íons $\mathbf{s}^{3,5}$. Considerando-se que, durante o tratamento ortodôntico, a canaleta dos braquetes está freqüentemente submetida à aplicação de forças, suspeita-se que esta variável possa estimular a maior liberação de níquel no ambiente bucal ${ }^{3}$.

Assim sendo, a proposta desta pesquisa foi: 1) avaliar a liberação de níquel por dois tipos de braquetes metálicos nacionais; 2) investigar a influência de dois tipos de soluções na liberação de níquel; 3) verificar se a aplicação de esforço mecânico altera a quantidade de níquel liberada pelos braquetes de aço inoxidável austenítico.

\section{MATERIAIS E MÉTODO}

Avaliou-se a influência de três variáveis sobre o processo de liberação de íons níquel: tipo de braquete, solução de imersão, e presença de torque no fio (esforço mecânico).

A composição e as características dos braquetes metálicos avaliados estão descritas no quadro 1 .

As soluções utilizadas para imersão dos braquetes metálicos foram: saliva artificial (0,4g NaCl; 0,4g KCl; 0, $795 \mathrm{CaCl}$. 2 $\mathrm{H}_{2} \mathrm{O} ; 0.78 \mathrm{~g}$ $\mathrm{NaH} 2 \mathrm{PO} 4.2 \mathrm{H}_{2} \mathrm{O} ; 0,005 \mathrm{~g} \mathrm{Na} 2 \mathrm{~S} .9 \mathrm{H}_{2} \mathrm{O} ; 1 \mathrm{~g}$ Uréia [CO( $\left.\left(\mathrm{NH}_{2}\right)_{2}\right] ; 1000 \mathrm{ml}$ de água destilada $)^{1}$ e solução aquosa salina $(\mathrm{NaCl} 0,05 \%)$.

Avaliou-se a influência do esforço mecânico (torque) na liberação de níquel dos braquetes Edgewise Standard. Para tanto, foi incorporado torque de $20^{\circ}$ em fio ortodôntico retangular $\left(0,021\right.$ ” x 0,025 ” Unitek ${ }^{\circledR}$ ref. 856.014), o qual gerou força binária no interior da canaleta. A torção do fio foi realizada utilizando-se chave de torque, alicate 142 e transferidor para padronização da angulação. Para gerar força no interior da canaleta, os braquetes foram colados com Super Bonder ${ }^{\circledR}$, em base acrílica confeccionada para este fim.

\section{SEQÜÊNCIA DO EXPERIMENTO}

Foram montados sete corpos de prova para cada um dos seis grupos experimentais e quatro corpos de prova para cada grupo controle, conforme o quadro 2 .

Os corpos de prova experimentais continham seis braquetes presos com amarrilho elástico (Morelli ${ }^{\circledR}$ ref.60.03.301) ao fio ortodôntico de aço inoxidável (Fig. 1). Os braquetes submetidos ao esforço mecânico foram colados em uma base plana de resina acrílica (Fig. 2) Os braquetes que não foram submetidos ao esforço mecânico tiveram suas bases cobertas por resina acrílica para evitar a liberação de elementos metálicos por estas áreas (Fig. 3). Confeccionou-se uma alça numa das extremidades do fio para estabilização do mesmo no tubo de ensaio, onde foram adicionados $10 \mathrm{ml}$ das respectivas soluções.

Os dois grupos controle foram representados por tubos contendo apenas as soluções e também por tubos contendo as soluções com um segmento de fio de aço inoxidável, igual ao utilizado nos grupos experimentais, porém sem braquetes (Quadro 2). As amostras, devidamente identificadas (Fig. 4), permaneceram a $37^{\circ} \mathrm{C}$, sob agitação constante, com umidade relativa do ar de $100 \%$, o que foi atingido utilizando-se o equipamento de Banho Dubnoff (Nova Tecnica ${ }^{\circledR}$ ) (Fig. 5). Após uma semana, foi realizada a renovação das soluções de todos os grupos experimentais e controle. As soluções removidas foram armazenadas sob refrigeração em frascos de vidro devidamente identificados. Decorrida a segunda semana, houve o término do experimento sendo as soluções novamente armazenadas em refrigerador. A medição das concentrações de níquel presente nas soluções, após 1 e 2 semanas, foi realizada com espectrofotômetro de absorção atômica (Varian - Spectra A55).

Os resultados obtidos foram avaliados estatisticamente aplicando-se os testes Mann-Whitney e Wilcoxon. 


\begin{tabular}{|c|c|c|}
\hline Braquete & AISI & $\begin{array}{c}\text { Composição química } \\
(\% \max )\end{array}$ \\
\hline $\begin{array}{l}\text { Edgewise Stan- } \\
\text { dard }^{* *} .022^{\prime \prime}\end{array}$ & $\begin{array}{c}\text { Aletas - AISI 303; } \\
\text { Base - AISI 304 }\end{array}$ & $\begin{array}{c}\text { Cr-25\% } \\
\text { Ni-20\% } \\
\text { Co-6\% } \\
\text { Mn-2\% } \\
\text { Si-2\% } \\
\text { Fe-restante }\end{array}$ \\
\hline $\begin{array}{c}\text { Monobloc }{ }^{\circledR} \\
\text { Sistema Roth } \\
\text {.022" }\end{array}$ & $\begin{array}{l}\text { Aço especial com } \\
\text { baixo teor de níquel }\end{array}$ & $\begin{array}{c}\mathrm{Cr}-17,5 \% \\
\mathrm{Mo}-3,5 \% \\
\mathrm{Ni}-0,01 \% \\
\mathrm{Mn}-12 \% \\
\mathrm{Si}-1 \% \\
\mathrm{~N}-1,2 \% \\
\mathrm{C}-0,1 \% \\
\text { Fe-restante }\end{array}$ \\
\hline
\end{tabular}

Quadro 1 - Características dos braquetes metálicos avaliados*.

*Fonte: Folha de segurança - Dental Morelli Ltda.

**Dental Morelli Ltda - referência 10.30.201.

***Dental Morelli Ltda - referência 10.15.200.

\begin{tabular}{|c|c|c|}
\hline GRUPO & Valor em $\mu g$ & Estatística* \\
\hline 1) Standard em $\mathrm{NaCl}$ & 8,500 & a \\
\hline 2) Standard em $\mathrm{NaCl}$ c/torque & 7,371 & a \\
\hline 3) Monobloc em $\mathrm{NaCl}$ & 1,229 & $b$ \\
\hline 4) Standard em Saliva & 8,214 & a \\
\hline 5) Standard em Saliva c/torque & 8,614 & a \\
\hline 6) Monobloc em Saliva & 4,029 & c \\
\hline C1 - Controle Saliva & 3,025 & c \\
\hline $\mathrm{C} 2$ - Controle $\mathrm{NaCl}$ & 1,550 & $\mathrm{~b}$ \\
\hline
\end{tabular}

${ }^{*}$ letras diferentes indicam diferença estatística para $p<0,05 \%$

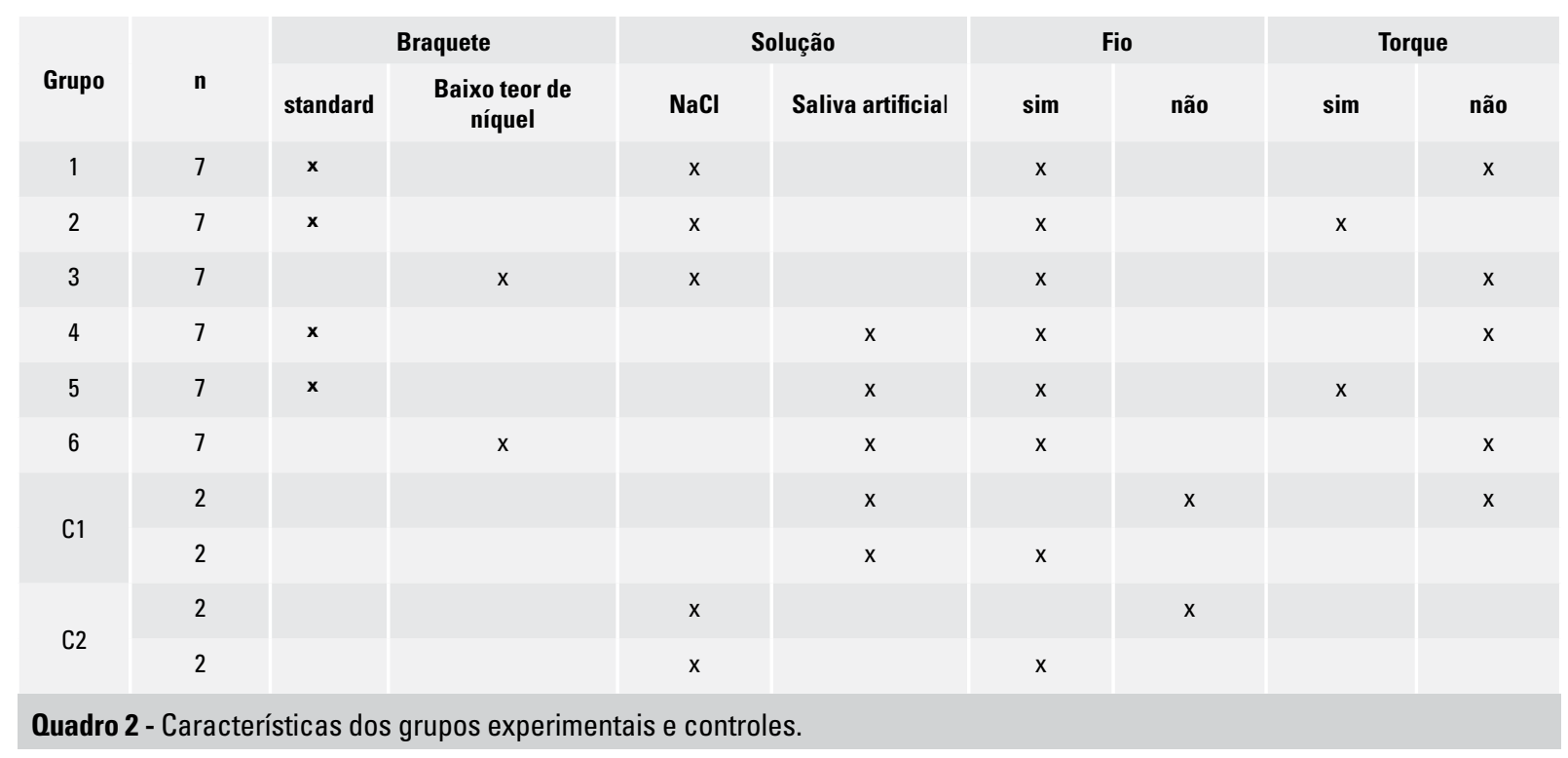

\section{RESULTADOS E DISCUSSÃO}

Os valores da liberação cumulativa de níquel, considerando a massa total liberada após as duas semanas do experimento, estão descritos na tabela 2 .

O gráfico 1 revela que a liberação de níquel pelos braquetes Standard foi significativamente maior que a quantidade liberada pelos braquetes Monobloc ( $\left.p<0,001 \_M a n n-W h i t n e y\right)$. Também se observou que os braquetes Standard liberaram maior quantidade de níquel na $2^{\mathrm{a}}$ semana
( $\mathrm{p}<0,001$ Wilcoxon), sendo que para os braquetes Monobloc a maior liberação ocorreu na primeira semana ( $p=0,004$ _Wilcoxon). Estes resultados indicaram que os braquetes Monobloc, fabricados com aço inoxidável de baixo teor de níquel, promoveram menor liberação deste elemento nas condições laboratoriais deste experimento.

A incorporação de esforço mecânico, avaliada nos braquetes Standard, não alterou as taxas de liberação de níquel nos períodos avaliados 
(p>0,7_Mann-Whitney) (Gráf. 2). Escassos são os estudos na literatura sobre a influência do torque na liberação de níquel por braquetes metálicos. Novos estudos que utilizem outros modelos expe-

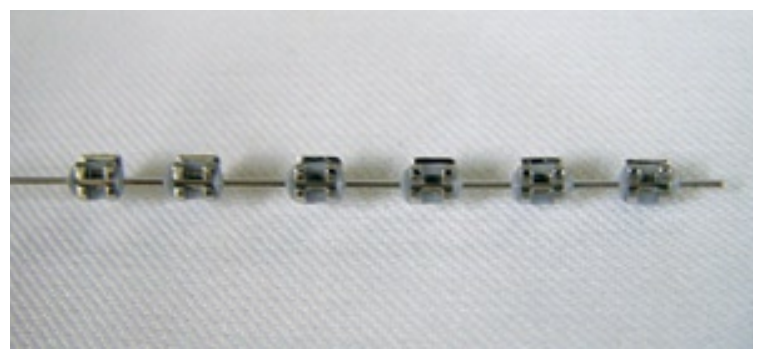

FIGURA 1 - Braquetes presos ao fio.

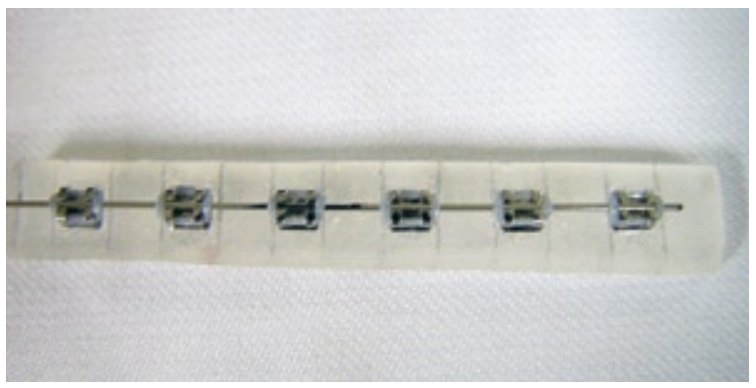

FIGURA 2 - Braquetes colados na base acrílica.

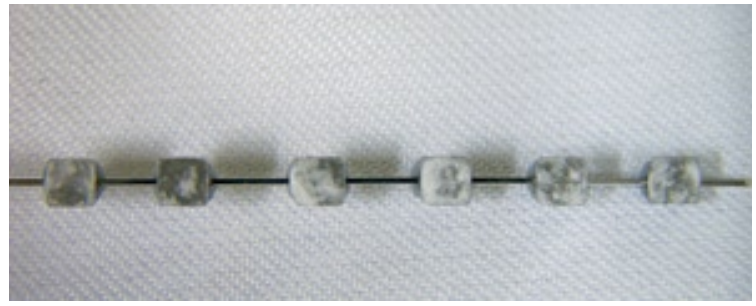

FIGURA 3 - Resina acrílica na base dos braquetes.

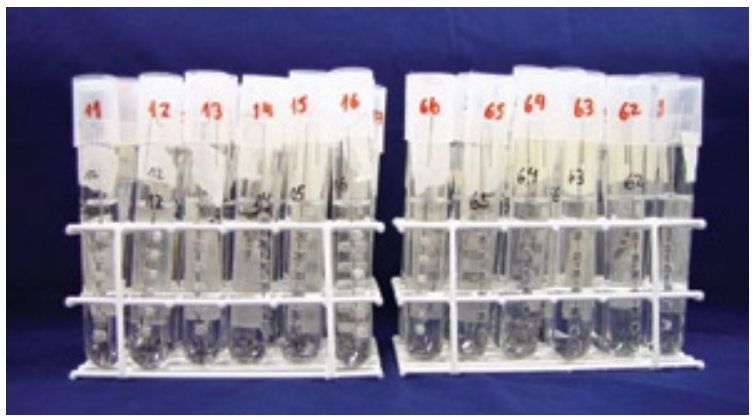

FIGURA 4 - Corpos de prova no interior dos tubos de ensaio, devidamente identificados. rimentais devem ser desenvolvidos a fim de investigar este aspecto.

O gráfico 3 mostra que, independentemente do tipo de braquete, e considerando o período total do experimento, não houve diferença na quantidade de níquel presente nos dois tipos de soluções empregadas ( $\mathrm{p}=0,573 \_$Mann-Whitney). Entretanto, avaliando-se as duas semanas separadamente, foi possível constatar que na segunda semana houve maior liberação de níquel na saliva artificial ( $\mathrm{p}=0,006 \_$Mann-Whitney). O gráfico 4, de freqüência acumulada, demonstra a liberação cumulativa de níquel pelos grupos ao longo das duas semanas do experimento. Nos grupos 1 e 2, em que os braquetes Standard foram imersos em solução salina, foi possível observar uma liberação mais linear, enquanto que nos grupos 4 e 5, nos quais os braquetes Standard foram imersos em saliva artificial, observou-se uma curva de liberação não linear com ascendência a partir da primeira semana (Gráf. 4).

O gráfico 5 evidencia a quantidade de níquel liberada de forma independente, na primeira e na segunda semana de avaliação.

Neste experimento, pôde-se observar que o braquete Standard liberou maior quantidade de níquel quando comparado ao braquete Monobloc (Gráf. 1, Tab. 2). Nota-se, também, que o braquete Monobloc apresentou um padrão de liberação de níquel semelhante aos grupos controles, o que confirma as afirmações do fabricante em relação

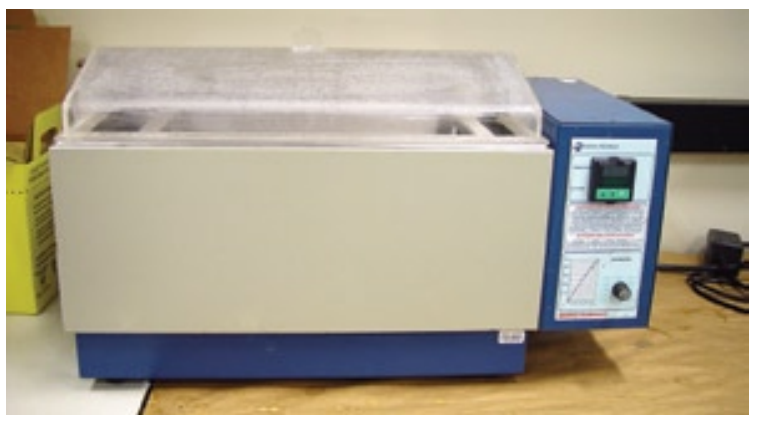

FIGURA 5 - Equipamento para banho Dubnoff com agitação e controle da temperatura. 


\begin{tabular}{|c|c|c|c|c|c|c|c|}
\hline Autores & Dispositivo & Ligas & $\begin{array}{l}\text { Soluções } \\
\text { de } \\
\text { imersão }\end{array}$ & Ambiente & $\begin{array}{l}\text { Troca da } \\
\text { solução }\end{array}$ & Tempo & Resultados \\
\hline $\begin{array}{c}\text { PARK e SHEARER } \\
(1983)\end{array}$ & $\begin{array}{l}\text { Aparelho } \\
\text { ortodôntico }\end{array}$ & $\begin{array}{l}\text { Aço inoxidável } \\
\text { austenítico - AISI } \\
304 \text { e } 303 S\end{array}$ & $\begin{array}{l}\mathrm{NaCl} \\
0,05 \%\end{array}$ & $\begin{array}{l}\text { Estático, com } \\
\text { tempera- } \\
\text { tura controlada } \\
\left(37^{\circ} \mathrm{C}\right)\end{array}$ & $\begin{array}{c}\text { Parcial, nos } \\
\text { dias } 3,6,9 \\
\text { e } 12\end{array}$ & 12 dias & $\begin{array}{c}40 \mu \mathrm{g} / \mathrm{dia} \text {, correspondente } \\
\text { ao aparelho fixo completo, } \\
\text { com bandas para dentes } \\
\text { posteriores }\end{array}$ \\
\hline $\begin{array}{c}\text { GRIMSDOTTIR, } \\
\text { GJERDET, e HEN- } \\
\text { STEN-PETTERSEN } \\
\text { (1992) }\end{array}$ & $\begin{array}{l}\text { Arcos extra- } \\
\text { bucais, arcos } \\
\text { ortodônticos, } \\
\text { bandas e } \\
\text { braquetes } \\
\text { metálicos }\end{array}$ & $\begin{array}{l}\text { Aço inoxidável } \\
\text { austenítico (diver- } \\
\text { sos tipos) }\end{array}$ & $\mathrm{NaCl} 0,9 \%$ & $\begin{array}{l}\text { Estático, com } \\
\text { controle da } \\
\text { temperatura } \\
\left(23^{\circ} \mathrm{C}\right)\end{array}$ & $\begin{array}{l}\text { Completa, } \\
\text { no dia sete }\end{array}$ & 14 dias & $\begin{array}{c}\text { Em média, } 0,131 \mu \mathrm{g} / \mathrm{bra}- \\
\text { quete/dia }\end{array}$ \\
\hline $\begin{array}{l}\text { KERUSUO, MOE, e } \\
\text { KLEVEN (1995) }\end{array}$ & $\begin{array}{l}\text { Aparelho } \\
\text { ortodôn- } \\
\text { tico fixo, arco } \\
\text { extrabucal e } \\
\text { quadrihélice }\end{array}$ & $\begin{array}{l}\text { Aço inoxidável } \\
\text { austenítico }\end{array}$ & $\mathrm{NaCl} 0,9 \%$ & $\begin{array}{l}\text { Estático e } \\
\text { dinâmico, } \\
\text { ambos em } \\
\text { temperatura } \\
\text { ambiente }\left(23^{\circ} \mathrm{C}\right)\end{array}$ & $\begin{array}{l}\text { Completa, } \\
\text { após duas } \\
\text { horas e } 24 \\
\text { horas. }\end{array}$ & 8 dias & $\begin{array}{c}22 \mu \mathrm{g} / \mathrm{dia} \text {, correspondente } \\
\text { ao aparelho fixo completo, } \\
\text { com bandas para dentes } \\
\text { posteriores }\end{array}$ \\
\hline $\begin{array}{c}\text { BARRET, BISHARA } \\
\text { e QUINN, J. K. } \\
\text { (1993) }\end{array}$ & $\begin{array}{l}\text { Aparelho or- } \\
\text { todôntico com } \\
\text { braquetes e } \\
\text { bandas }\end{array}$ & $\begin{array}{l}\text { Aço inoxidável } \\
\text { austenítico - AISI } \\
\text { 303, 304, } 304 \text { e } 316 \\
\text { e níquel - titânio }\end{array}$ & $\begin{array}{l}\text { Saliva } \\
\text { artificial }\end{array}$ & $\begin{array}{l}\text { Dinâmico, } \\
\text { com agitação } \\
\text { e tempera- } \\
\text { tura controlada } \\
\left(37^{\circ} \mathrm{C}\right)\end{array}$ & $\begin{array}{l}\text { Completa, } \\
\text { semanal }\end{array}$ & 28 dias & $\begin{array}{c}26 \mu \mathrm{g} / \mathrm{dia} \text {, correspondente } \\
\text { ao aparelho fixo completo, } \\
\text { com bandas para dentes } \\
\text { posteriores }\end{array}$ \\
\hline TAl et al. (1992) & $\begin{array}{l}\text { Coroas me- } \\
\text { tálicas }\end{array}$ & $\mathrm{Ni}-\mathrm{Cr}$ & $\begin{array}{l}\text { Saliva } \\
\text { artificial }\end{array}$ & $\begin{array}{l}\text { Dinâmico, } \\
\text { com agitação } \\
\text { e tempera- } \\
\text { tura controlada } \\
\left(37^{\circ} \mathrm{C}\right)\end{array}$ & $\begin{array}{l}\text { Contínua } \\
\text { (fluxo de } \\
2 \mathrm{ml} / \mathrm{min} \text { ) }\end{array}$ & $\begin{array}{c}12 \\
\text { meses }\end{array}$ & $\begin{array}{l}100 \mu \mathrm{g} / \text { dia por cada coroa } \\
\text { total metálica de } \mathrm{Ni}-\mathrm{Cr}\end{array}$ \\
\hline Esta pesquisa & $\begin{array}{l}\text { Braquetes } \\
\text { metálicos e fio } \\
\text { ortodôntico }\end{array}$ & $\begin{array}{l}\text { Aço inoxidável } \\
\text { austenítico AISI } \\
303 \text { e com baixo } \\
\text { teor de níquel }\end{array}$ & $\begin{array}{l}\text { Saliva } \\
\text { artificial } \\
\text { e } \mathrm{NaCl} \\
0,05 \%\end{array}$ & $\begin{array}{l}\text { Dinâmico, } \\
\text { com agitação } \\
\text { e tempera- } \\
\text { tura controlada } \\
\left(37^{\circ} \mathrm{C}\right)\end{array}$ & $\begin{array}{l}\text { Completa, } \\
\text { após } 7 \text { dias }\end{array}$ & 14 dias & $\begin{array}{c}\text { De } 2,42 \mu \mathrm{g} / \mathrm{dia} \text { a } 0,34 \mu \mathrm{g} / \mathrm{dia} \\
\text { correspondente ao aparelho } \\
\text { fixo completo, dependendo } \\
\text { do tipo de braquete e do tipo } \\
\text { de solução }\end{array}$ \\
\hline
\end{tabular}

a não liberação de elementos metálicos no ambiente oral.

O modelo experimental adotado nesta pesquisa mostrou-se satisfatório, pois, conforme ilustra o gráfico 4 , os grupos semelhantes, tais como os 1 e 2, 4 e 5, 6 e Cl (controle de saliva), 3 e C2 (controle de solução salina), apresentaram curvas similares de liberação de níquel.

$\mathrm{Na}$ presente pesquisa, a liberação de níquel foi crescente com o tempo, corroborando com os resultados encontrados por Wataha, Lockwood ${ }^{23}$; Grimsdottir, Gjerdet, Hensten-Pettersen ${ }^{8}$ e Huang et $\mathrm{al}^{9}$. Por outro lado, Barret, Bishara e Quinn ${ }^{1}$, que realizaram a troca semanal da solução de imersão, encontraram que a liberação máxima ocorreu após sete dias, havendo redução da quantidade de níquel liberada após este período.

Cada tubo de ensaio desta pesquisa continha 6 braquetes e um segmento de fio, ou seja, a quantidade aproximada de metal presente em uma hemi-arcada de aparelho ortodôntico fixo colado, sem a utilização de bandas. Sendo assim, a massa de níquel presente em cada tubo de ensaio pode ser multiplicada por quatro, para corresponder à quantidade de metal presente em ambas as arcadas completas. Este raciocínio também foi utilizado para cálculo da liberação de níquel pelo aparelho ortodôntico completo nas pesquisas de Park, Shearer ${ }^{20}$; Barret, Bishara, Quinn'; Huang, Shin e $\mathrm{Cha}^{10}$. Portanto, para obtenção da liberação de níquel correspondente ao aparelho fixo completo, sem bandas, para ambas as arcadas, pode-se mul- 


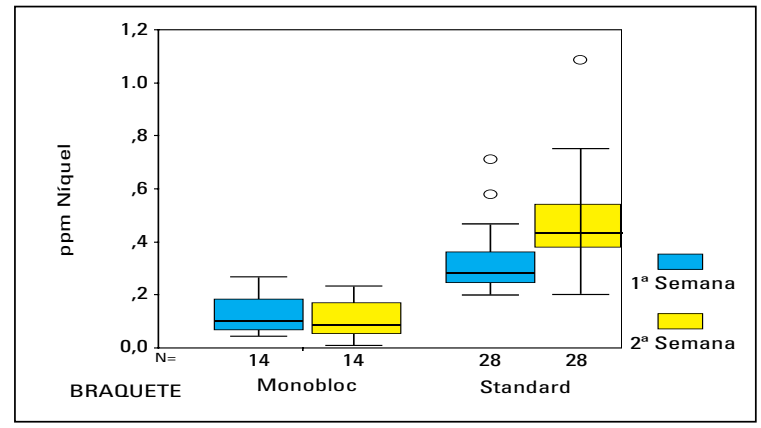

Gráfico 1 - Liberação de níquel dos braquetes metálicos avaliados.

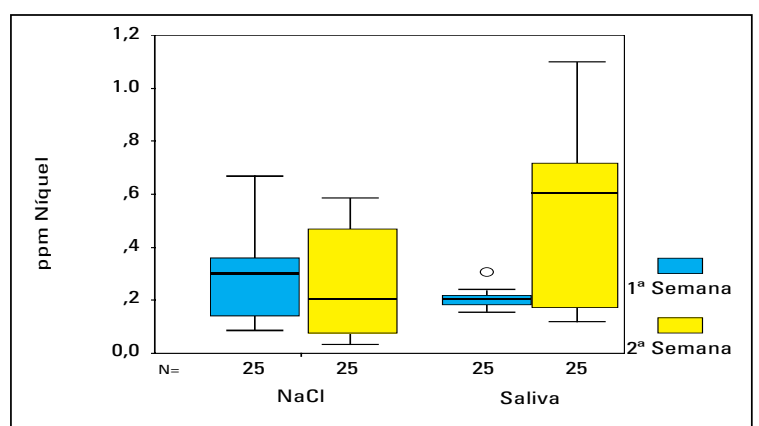

Gráfico 3 - Liberação de níquel nas duas soluções avaliadas.

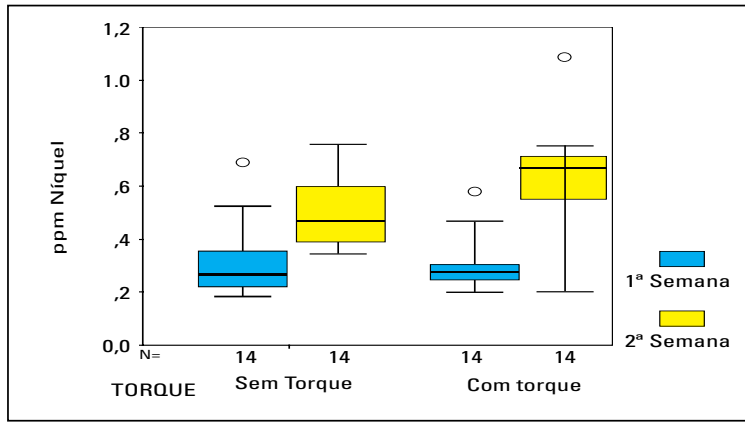

Gráfico 2 - Liberação de níquel com e sem esforço mecânico.

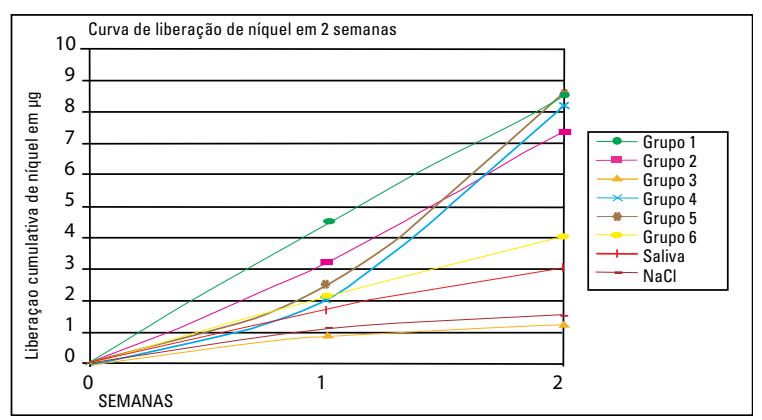

Gráfico 4 - Freqüência acumulada da liberação de níquel no período avaliado.

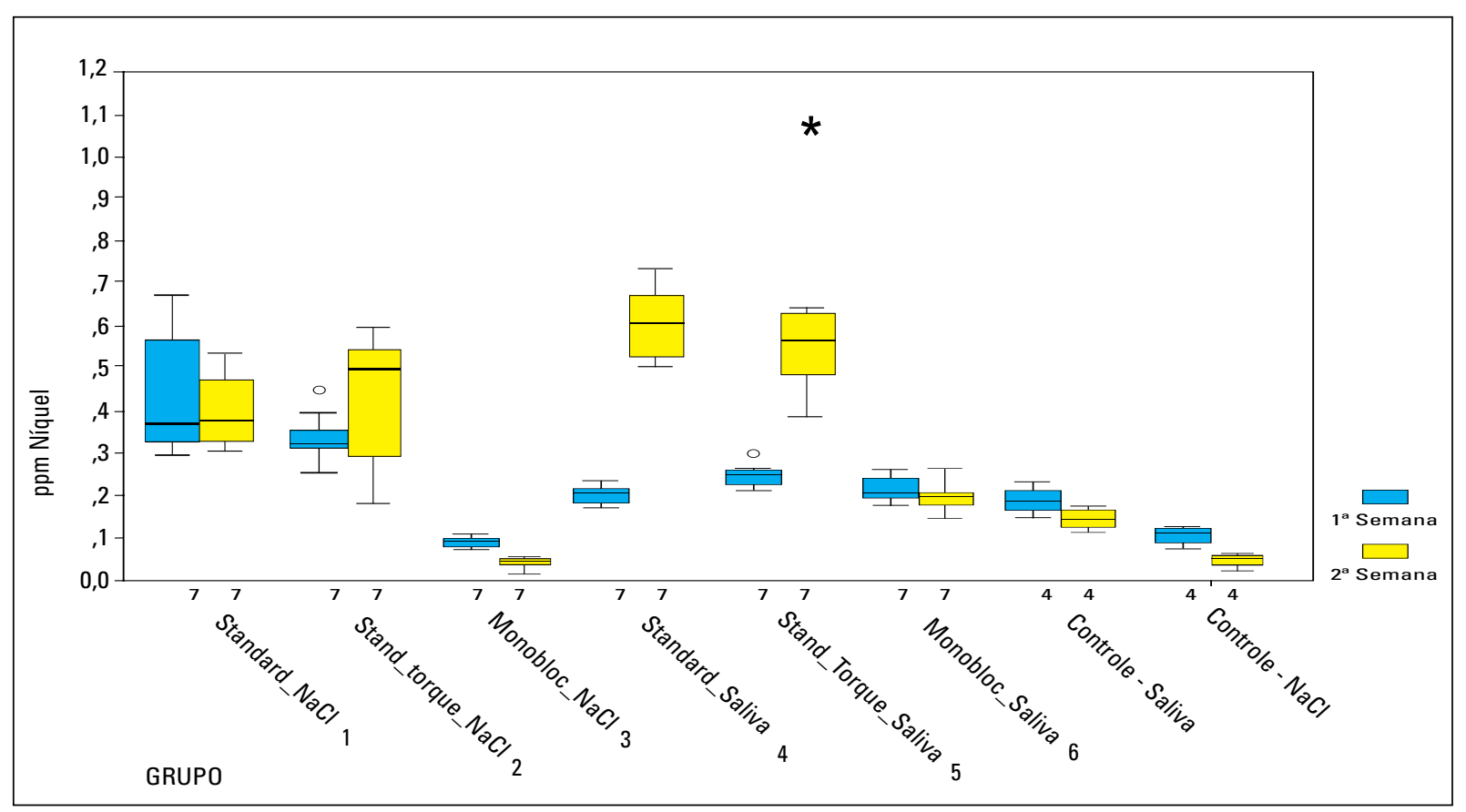

Gráfico 5 - Liberação de níquel pelos grupos experimentais. 
tiplicar por quatro os valores apresentados na tabela 2. O produto dividido por quatorze, neste caso, indica a liberação diária de níquel.

O quadro 3 sintetiza os resultados obtidos em alguns trabalhos de liberação de níquel. A comparação entre a quantidade de íons liberada nos diversos experimentos in vitro descritos na literatura ${ }^{1,8,9,10,20,22}$ apresenta ressalvas, pois a quantidade de metal utilizada, o tipo de solução e a metodologia empregada são bastante heterogêneos, limitando a comparação dos resultados.

\section{CONCLUSÕES}

O presente estudo, com a metodologia adotada permitiu, verificar que:

1) os braquetes convencionais liberaram quan- tidades significativas de níquel, independente da solução de imersão.

2) os braquetes com baixo teor de níquel não liberaram quantidades significativas deste elemento em nenhuma das soluções, sendo os valores encontrados semelhantes aos dos respectivos grupos controle.

3) O tipo de solução utilizada para imersão dos braquetes metálicos modificou o padrão de liberação de níquel.

4) A presença de esforço mecânico (torque), neste modelo experimental, não aumentou a liberação de níquel pelos braquetes avaliados.

Enviado em: Julho de 2003 Revisado e aceito: Fevereiro de 2005

\title{
In vitro nickel release from metallic orthodontic brackets
}

\begin{abstract}
Austenitic stainless steel is frequently used to fabricate orthodontic appliances, which contains 8-10\% of nickel. Such metal is responsible for hypersensitivity allergic reactions. Thus, nickel release of orthodontic appliances may be responsible for contact dermatitis in sensitive patients. This study assessed the influence of three variables in nickel release of metal brackets: 1) type of metal alloy; 2) type of solution used for immersion; and 3) mechanical stress. Six experimental and two control groups were assessed. The specimens were immersed in saline solution or artificial saliva, maintained in constant agitation in controlled temperature environment $\left(37^{\circ} \mathrm{C}\right)$. Nickel present in solutions was measured with atomic spectroscopy (Varian-Spectra A55) in two moments: after one and after two weeks. The results showed that brackets made of low nickel contend alloy released less nickel than standard ones. It was possible to notice that the type of solution alters the pattern of nickel release. Mechanical stress applied in the slots of standard brackets did not influence nickel release.
\end{abstract}

Key words: Metals. Orthodontic. Nickel. Metal brackets. 


\section{REFERÊNCIAS}

1. BARRET, R. D.; BISHARA, S. E.; QUINN, J. K. Biodegradation of orthodontic appliances. Part I. Biodegradation of nickel and chromium in vitro. Am J Orthod Dentofacial Orthop, St. Louis, v. 103, no.1, p. 8-14, Jan. 1993.

2. BISHARA, S. E. Oral lesion caused by an orthodontic retainer: a case report. Am J Orthod Dentofacial Orthop, St. Louis, v.108, no. 2, p. 115-17, Aug. 1995

3. ELIADES, T.; ATHANASIOU, A. E. In vivo aging of orthodontic alloys: implications for corrosion potential, nickel release, and biocompatibility. Angle Orthod, Appleton, v. 72, no. 3, p. 222237, June 2002

4. EUROPEAN PARLIAMENT AND COUNCIL DIRECTIVE 94/27/EEC. Official Journal of the European Communities, Brussels, 1994.

5. FONTANA, M. G. Corrosion Engineering. 3rd ed. New York: Donneco Internacional, 1986.

6. FRAUNNHOFER, J. A. Corrosion of Orthodontic Devices. Semin Orthod, Philadelphia, v. 3, no. 3, p.198-205, Sept. 1997.

7. GREIG, D, G. M. Contact dermatitis reaction to a metal buckle on a cervical headgear. Br Dent J, London, v.155, no. 2, p. 61, July 1983.

8. GRIMSDOTTIR, M. R.; GJERDET, N. R.; HENSTEN-PETTERSEN, A. Composition and in vitro corrosion of orthodontic appliances. Am J Orthod Dentofacial Orthop, St. Louis, v. 101, no. 6, p. 525-32, June 1992

9. HUANG, T. et al. Comparison of ion release from new and recycled orthodontic brackets. Am J Orthod Dentofacial Orthop, St. Louis, v. 120, no.1, p. 68-75, July 2001.

10. HWANG, C.; SHIN, J.; CHA, J. Metal release from simulated fixed orthodontic appliances. Am J Orthod Dentofacial Orthop, St. Louis, v. 120, no. 4, p.383-391, Oct, 2001

11. JANSON, G. P. R. et al. Avaliação clínica da reação de hipersensibilidade ao níquel nos pacientes em tratamento ortodôntico. Ortodontia, São Paulo, v. 27, n.2, p. 31-37, maio/ago. 1994
12. JONES, T. K . et al. Dental implications of nickel hypersensitivity. J Prosthet Dent, St. Louis, v. 56, no. 4, p. 507-509, Oct. 1996

13. KEROSUO, H.; MOE, G.; KLEVEN, E. In vitro release of nickel and chromium from different types of simulated orthodontic appliances. Angle Orthod, Appleton, v. 65, no. 2, p.111-116, Mar. 1995

14. KOHL, R. W. Metallurgy in Orthodontics. Am J Orthod Dentofacial Orthop, St. Louis, v. 34, no.1, p. 37-52, Jan. 1964.

15. LOWEY, M. N. Allergic contact dermatitis associated with the use of an Interlandi headgear in a patient with a history of atopy. Br Dent J, London, v.175, no. 24, p. 67-72, July 1993.

16. MAIJER, R. I.; SMITH, D. C. Biodegradation of the orthodontic bracket system. Am J Orthod Dentofacial Orthop, St. Louis v. 90, no. 3, p.195-8, Sept. 1986

17. MENEZES, L. M. et al. Reação alérgica em paciente ortodôntico: um caso clínico. Ortodontia Gaúcha, Porto Alegre, v. I, n. 1 p. 51-6, abr. 1997

18. MORAES, S. et al. In vitro osteoblastic differentiation of human bone marrow cells in the presence of metal ions. J Biomed Mat Res, [s.l.], v. 44, no. 2, p.176-190, Feb, 1999.

19. NIPERA. Nickel Producers Environmental Research Association. Disponível em: < http://www.nipera.org >. Acesso em: 25 jan. 2003.

20. PARK, H. Y.; SHEARER, T. R. In vitro release of nickel and chromium from simulated orthodontic appliances. Am J Orthod Dentofacial Orthop, St. Louis, v. 84, no. 2, p.156-159, Aug. 1983

21. PELTONEN, L. Nickel sensitivity $\mathrm{n}$ the general population Contact Derm, Copenhagen, v. 5, no. 1, p. 27-32, Jan. 1979.

22. TAl, Y. et al. Leaching of nickel, chromium, and beryllium ions from base metal alloy in artificial oral environment. J Prosthet Dent, St. Louis, v. 68, no. 4, p. 692-697, Oct. 1992

23. WATAHA, J. C.; LOCKWOOD, P. E. Release of elements from dental casting alloys into cell-culture medium over 10 months. Dent Mater, Copenhagen, v. 14, no. 2 p. 158-163, Mar. 1998

\section{Endereço para correspondência}

Marina Lara Sória

Secretaria de pós-graduação - PUCRS.

Avenida Ipiranga, 6681 - Prédio 6

Fone: (51) 3320-3562 Fax: (51) 3320-3626

E-mail: marinalarasoria@terra.com.br. 